\title{
Experiences and attitudes about physical activity and exercise in patients with chronic pain: a qualitative interview study
}

This article was published in the following Dove Press journal: Journal of Pain Research

\author{
Linn Karlsson' \\ Björn Gerdle' \\ Esa-Pekka Takala ${ }^{2}$ \\ Gerhard Andersson ${ }^{3,4}$ \\ Britt Larsson' \\ 'Pain and Rehabilitation Centre, \\ Department of Medical and Health \\ Sciences, Linköping University, \\ Linköping, Sweden; ${ }^{2}$ Work-related \\ Diseases, Finnish Institute of \\ Occupational Health, Helsinki, \\ Finland; ${ }^{3}$ Department of Behavioural \\ Sciences and Learning, Swedish \\ Institute for Disability Research, \\ Linköping University, Linköping, \\ Sweden; ${ }^{4}$ Department of Clinical \\ Neuroscience, Psychiatry Section, \\ Karolinska Institute, Stockholm, \\ Sweden
}

Purpose: The purpose of this study was to describe how patients with chronic pain experience physical activity and exercise (PA\&E).

Method: This qualitative interview study included 16 women and two men suffering from chronic pain and referred to a multimodal pain rehabilitation program. Semi-structured interviews were conducted and qualitative content analysis was used to analyze the interviews.

Results: One main theme emerged: "To overcome obstacles and to seize opportunities to be physically active despite chronic pain." This main theme was abstracted from five themes: "Valuing a life with physical activity," "Physical activity and exercise - before and after pain," "A struggle - difficulties and challenges," "The enabling of physical activity," and "In need of continuous and active support."

Conclusion: Although these participants valued PA\&E, they seldom achieved desirable levels, and performance of PA\&E was undermined by difficulties and failure. The discrepancy between the intention to perform physical activity and the physical activity accomplished could be related to motivation, self-efficacy, and action control. The participants desired high-quality interaction with healthcare providers. The findings can be applied to chronic pain rehabilitation that uses PA\&E as treatment.

Keywords: chronic pain, experiences, physical activity, rehabilitation, qualitative content analysis

\section{Introduction}

Chronic pain is a significant health problem that leads to major consequences for the individuals afflicted, their families, and society. ${ }^{1,2}$ Currently, there are in general no curative options for chronic pain, so treatments focus on reducing pain and disability. ${ }^{3,4}$ Physical activity and physical exercise are commonly prescribed as treatment for chronic pain. ${ }^{3,5}$ Physical activity is defined as any bodily movement produced by skeletal muscles that results in energy expenditure. ${ }^{6}$ Physical exercise is described as a subset of physical activity characterized by planned, structured, and repetitive physical activities with an objective to maintain or improve physical fitness. ${ }^{6}$ Because the terms physical activity and physical exercise are often used interchangeably in the literature, the term physical activity and exercise (PA\&E) is used in this study.

PA\&E interventions for chronic pain patients can include aerobic exercises, ${ }^{7,8}$ strength exercises, ${ }^{7,9}$ and motor control exercises. ${ }^{10,11}$ PA\&E as treatment has shown significant improvements (up to medium effect sizes) for pain intensity, physical disability, and psychological distress in chronic neck pain, chronic low back pain,
Pain and Rehabilitation Centre

Department of Medical and Health

Sciences, Linköping University,

SE-58I 85 Linköping, Sweden

Tel +46 I0 I0 34952

Fax +46 101034906

Email britt.larsson@liu.se 
and fibromyalgia..$^{8,9,12,13}$ Despite these benefits, challenges associated with PA\&E treatment, such as adherence to prescribed PA\&E, need further investigation. ${ }^{14,15}$ For example, patients who do not adhere to prescribed PA\&E treatment regime might experience smaller improvements than if they adhered to the prescribed PA\&E regime. ${ }^{14,15}$ Adherence to a PA\&E treatment regime might be affected by a wide range of personal and social factors such as self-efficacy and selfregulatory capabilities as well as support from others. ${ }^{16,17}$ Furthermore, symptoms and characteristics of different health problems, including an individual's psychological state may affect adherence to PA\&E. ${ }^{18}$ Moreover, as chronic pain entails barriers to the performance of a PA\&E treatment regime, the need for professional support has been described earlier. ${ }^{19}$ However, a qualitative review on beliefs about physical exercise for the management of chronic low back pain highlights the lack of studies that focus on participants' beliefs about exercise and on factors that influence patient adherence. ${ }^{20}$ Thus, although PA\&E has been found to be a valuable treatment for chronic pain, ${ }^{8,9,12,13}$ there is still a need to clarify how to apply PA\&E in chronic pain treatment in order to achieve optimal adherence. A deeper understanding of how chronic pain patients experience PA\&E is essential for a better understanding about how PA\&E should be applied to optimize PA\&E treatment for chronic pain. To address this gap in knowledge, this study describes how patients with chronic pain experience PA\&E.

\section{Materials and methods}

\section{Setting and procedures}

This qualitative interview study was performed at The Pain and Rehabilitation Center, University Hospital (Linköping, Sweden), a center that specializes in complex acute and chronic pain conditions. Sampling from a complete target population ${ }^{21}$ was used to access the sources rich of information to enable the exploration of important details about how patients with chronic pain experience PA\&E. The recruitment procedure consecutively followed the Pain and Rehabilitation Center's ordinary flow of patients between January 2016 and June 2016. The potential participants include all patients during this time period (49 patients) who were scheduled for a 6-week multidisciplinary pain rehabilitation program, but who had not started any rehabilitation. All the eligible patients were mailed a letter that described the study. After 1 week, the presumptive participants were contacted through telephone by one of the authors (LK). During this conversation, the prospective participants received more information about the study. If the patient decided to participate, a date for an interview was scheduled. The regional Ethical Review Board in Linköping approved the study (DN: 2014/27931). The Code of Ethics of the World Medical Association, Declaration of Helsinki, ${ }^{22}$ was applied. All the participants signed informed consent before participating in the study.

\section{Participants}

Of the 49 eligible patients, 16 women and two men agreed to participate (21 women and 10 men declined participation). The mean age of the participants was 47 years (SD 11), and the mean age of those who declined to participate was 41 years (SD 11). Inclusion criteria were chronic pain (pain duration more than 3-6 months ${ }^{23}$ ) with no further pharmacological or invasive treatment options, age 18-65 years, ability to speak and understand Swedish, and assessed by a specialized physician to be suitable for participation in a multidisciplinary pain rehabilitation program. The only exclusion criterion was severe psychiatric illness.

\section{Background characteristics of the participants}

Data about the following background characteristics were collected: pain intensity, pain locations, pain duration, education, occupational status, and marital status. In addition, the participants completed questionnaires about their level of PA\&E and about psychological aspects related to chronic pain. The background information data were summarized after the qualitative analysis of the interviews was performed. The background characteristics are presented to offer a basic background information about the group of patients who participated in the study.

Information about PA\&E level was collected using the short form of the International Physical Activity Questionnaire (IPAQ), ${ }^{24}$ which identifies three categories (levels) of physical activity. ${ }^{25}$ Category 1 (low) includes inactive individuals who do not fulfill criteria for category 2 or 3 . Category 2 (moderate) includes individuals who perform vigorous activity at least 20 minutes per day 3 days per week, or who perform moderate-intensity activities or walk at least 30 minutes per day 5 days per week, or who perform 5 or more days of a combination of walking, moderate-intensity or vigorous-intensity activities to at least 600 metabolic equivalent per task (MET)-minutes per week. Category 3 (high) includes individuals who perform at least 3 days of vigorous-intensity activities and accumulate at least 1500 MET-minutes per week, or 7 or more days of a combination of walking, moderate-intensity or vigorous-intensity activities for at least 3000 MET-minutes per week. Symptoms of 
depression and anxiety were measured using the Hospital Anxiety and Depression Scale (HADS, total score range for anxiety and depression: 0-21). The HADS cutoff points for each subscale is $>8$, for a score that indicates possible anxiety or depression, and a score $>11$ indicates a probable anxiety or depression. ${ }^{26,27}$ Pain self-efficacy (ie, one's confidence in performing tasks despite pain) was measured using the Pain Self-Efficacy Questionnaire (PSEQ, total score range: $0-60)$. A higher score indicates a higher pain self-efficacy. ${ }^{28}$ Pain-related fear-avoidance beliefs were measured using the Fear Avoidance Beliefs Questionnaire (FABQ), which includes two subscales - physical activity (total score range: 0-24) and work (total score range: $0-42$ ). ${ }^{29} \mathrm{~A}$ high score for FABQ-physical activity has been proposed to be $>15,{ }^{30}$ and a high score for FABQ-work has been proposed to be $>34 .{ }^{31}$ Pain-related psychological inflexibility was measured using the Psychological Inflexibility in Pain Scale (PIPS, total score range: 16-112). A higher score indicates more psychological inflexibility. ${ }^{32}$ SPSS statistical program for Windows (version 23.0) was used for analyzing description data of background characteristics.

\section{Background characteristics}

Pain intensity (median [min, max]) during the previous week per a numeric rating scale $(0-10)$ was $4.6(1,9)$. Three participants reported neck, back, and head pain. Two of them additionally reported pain in legs and arms, and 15 participants had widespread pain according to The American College of Rheumatology 1990 Criteria. ${ }^{33}$ Four participants reported a pain duration of 1-5 years, six participants reported a pain duration of 5-10 years, and six participants reported a pain duration of $>10$ years. Two participants had missing data regarding pain duration. Eight participants had secondary upper level or vocational education, and 10 had university education. Eleven participants received full compensation from the health insurance system, four were working full time, and three were working part time. Two participants lived alone, 15 lived with someone, and one participant had missing data regarding living situation. Physical activity previous week (IPAQ) was low for six participants, moderate for 10 participants, and high for two participants. The most common PA\&E activity was walking. The following psychological factors were reported (median [min, $\max ])$ : anxiety (HADS), $5.0(0,19)$; depression (HADS), $6.5(1,19)$; pain self-efficacy (PSEQ), 34 (5, 59); fear-avoidance beliefs (FABQ) physical activity, $12(3,21)$; fear-avoidance beliefs (FABQ) work 20 $(2,42)$; and psychological inflexibility (PIPS), $76(30,110)$.

\section{Interviews}

All interviews were conducted individually at the Pain and Rehabilitation Centre in a secluded and comfortable interview room. The participants were all interviewed by LK using a semistructured interview guide based on principles outlined by Kvale and Brinkmann. ${ }^{34}$ The semistructured interview guide consisted of three main questions: 1) Tell me about your experiences with PA\&E, 2) Tell me about your motivation to perform PA\&E, 3) Tell me about your experiences with PA\&E as treatment for your pain. When more elaborations were needed, the main questions were followed by subquestions. All interviews were performed in Swedish as the participants and the interviewer were native Swedish. The interviews lasted in general between 30 and 45 minutes, were audio recorded, transcribed verbatim, and translated into English by the authors. The interviews and the transcribed text were handled anonymously (the participants were not identified in the recordings or in the transcripts).

\section{Analysis}

To understand the meaning of the content of the interviews and to get a deeper understanding about the research topic, the text was analyzed using qualitative content analysis with an inductive approach (categories were derived from the interview text). ${ }^{35,36}$ The present analysis explores the manifest and to some extent the latent content of the interviews. ${ }^{37,38}$ That is, the analysis includes a certain degree of interpretation of the underlying meaning of the content in the interviews. Each interview was considered a unit of analysis. During the analysis, two of the authors (LK and BL, both experienced in clinical management of chronic pain) thoroughly discussed each step to enhance trustworthiness of the findings. The analysis started with reading the interview text several times to get an understanding and a shared sense of the whole. The next step included identification of meaning units as related to the aim of the study. The software NVivo 10 (QSR International Pty Ltd. Version 10, 2012) was used for the practical procedures of the analysis. The meaning units were labeled with codes, and codes with similar content were grouped into categories. The categories were interpreted and abstracted into themes. The analysis process included continuous back and forth work among the meaning units, codes, categories, and themes. Thus, the results of this study were developed through LK's and BL's continuous discussions, reflections, and agreements, which were based on consensus and directed by the aim of the study. Table 1 shows examples of meaning units, codes, categories, and a theme. 
Table I Example of meaning units, codes, categories, and a theme

\begin{tabular}{|c|c|c|c|c|}
\hline \multirow{3}{*}{$\begin{array}{l}\text { Theme } \\
\text { Categories } \\
\text { Codes }\end{array}$} & \multicolumn{4}{|c|}{ Valuing a life with physical activity } \\
\hline & \multicolumn{2}{|c|}{ A lack of physical activity and exercise } & \multicolumn{2}{|l|}{ Values } \\
\hline & Frustration & Lost hope & The ability to be active & Rather than medication \\
\hline Meaning units & $\begin{array}{l}\text { I can be frustrated, because } \\
\text { I know by myself, I have } \\
\text { worked a lot with my body. } \\
\text { I have exercised so much } \\
{[\ldots] \text { and I can be irritated at }} \\
\text { physiotherapists when they } \\
\text { say, "Well, now we must } \\
\text { go back to step one. You } \\
\text { must do these exercises" } \\
\text { [Interviewee (IN) 5] }\end{array}$ & $\begin{array}{l}\text { But she gave up on me. She } \\
\text { said, "I will not be able to help } \\
\text { you, because your body do not } \\
\text { respond." And then I lost my } \\
\text { hope [IN 9] }\end{array}$ & $\begin{array}{l}\text { And then, unfortunately it has } \\
\text { been worse again. And then it } \\
\text { has been very valuable for me to } \\
\text { be able to walk [IN 6] } \\
\text { [...] It makes it possible for me } \\
\text { to be active, and I like it, it is } \\
\text { quality for me [...] [IN I0] }\end{array}$ & $\begin{array}{l}\text { Yes, I have had such strong } \\
\text { pain killers when I was trying } \\
\text { to sleep. But the tablets made } \\
\text { me feel so bad. I am very easily } \\
\text { affected by medication, so I } \\
\text { rather want to be able to solve } \\
\text { the pain problem myself with } \\
\text { the help of exercise [IN I3] }\end{array}$ \\
\hline
\end{tabular}

Note: The interviews were conducted in Swedish and the responses were translated into English by the authors.

\section{Results}

The analysis resulted in one main theme: "To overcome obstacles and to seize opportunities to be physically active despite chronic pain." This main theme was abstracted from five themes (Figure 1): "Valuing a life with PA\&E," "PA\&E and exercise - before and after pain," "A struggle - difficulties and challenges," "The enabling of PA\&E," and "In need of continuous and active support." In the interviews, the words "physical activity" and "exercise" were used by the patients to describe moving the body and performing desirable actions. For these patients, "physical activity" and "exercise" included a variety of activities such as house work, gardening, walking, jogging, cycling, training at the gym, and ball games. The word "exercise" for activities more intense than everyday activities were also expressed. However, it was not possible to identify a clear difference between physical activity and physical exercise in the interviews. Therefore, we combined the two ideas to a single term "physical activity and exercise (PA\&E)."

\section{Valuing a life with physical activity}

Inclusion of PA\&E in daily life was described as highly valued and desirable even though the actual performance of PA\&E could be difficult. Ambitions to be physically active despite pain were expressed, and the patients also had a desire to engage in more PA\&E in their daily life. PA\&E was perceived as a basic need.

It [PA\&E] really means a lot to me, like as to eat and sleep. It has been a very basic thing for me and it is a big part of my personality, so very important. [...] I cannot emphasize enough the importance PA\&E has for me. [Interviewee (IN) 10]

Furthermore, PA\&E was expressed as being a prerequisite for other activities leading to a better quality of life. The patients also valued PA\&E because they assumed it would lead to short-term as well as long-term health benefits. Regular PA\&E was thought to prevent diseases and illnesses, and an expectation of decreased pain was one prominent reason for being physically active. Similarly,

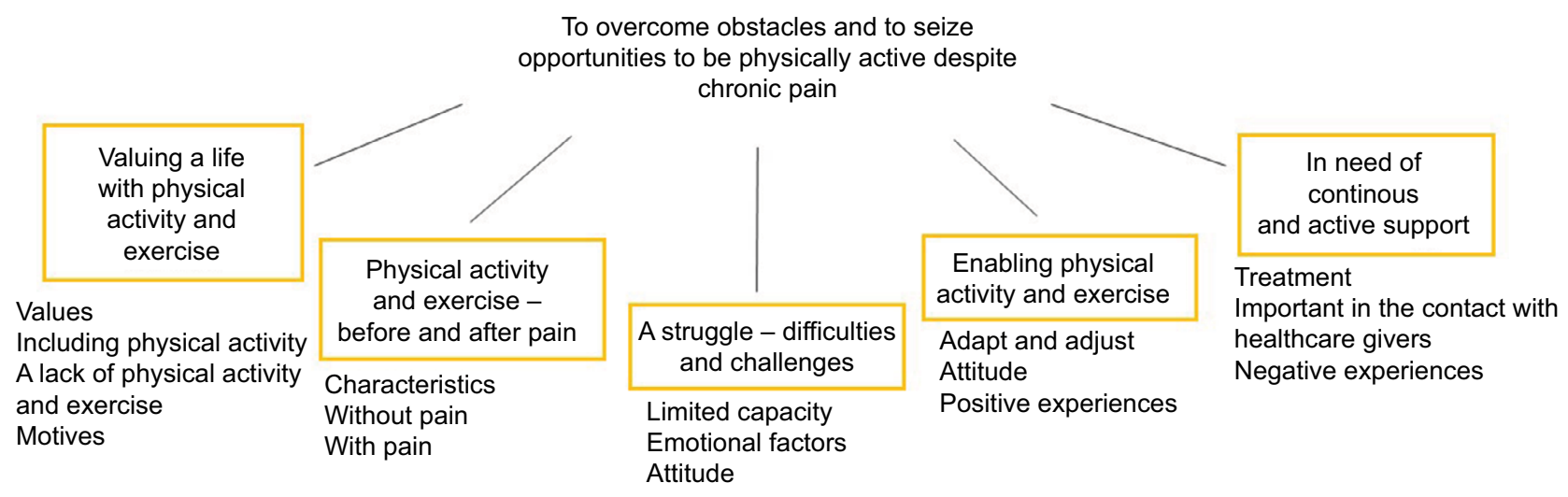

Figure I Overview of the results including the main theme, the themes, and the categories. 
mental wellness was an important reason for performing PA\&E, as patients thought PA\&E would help with mental relaxation and mental focus. PA\&E was also viewed as invigorating and strengthening and as such a reason to be physically active.

When I have been more active so to say, of course I feel the effect of it. This is positive that I can do more, have more energy, and feel better. I get better condition and become stronger, both physically and mentally stronger as well. [IN 9]

Furthermore, PA\&E contributed to an experience of freedom and autonomy, the ability to make independent choices about daily life. Being physically active was experienced as an important part of the identity and not being able to perform PA\&E led to distress.

It is basically that it [PA\&E] means everything. It is sort of [...] if it is not present in my life, then I cannot have a life. The body doesn't want anything then. You become more positive if you try to exercise, even if it is though, you feel better afterwards. [IN 6]

An experience of less PA\&E than desired was described as related to impaired quality of life, and lack of PA\&E was associated with a negative state of mind.

[Without PA\&E] [...] I mean, it basically affects your whole life. You become sluggish, and the life becomes much more boring. You become a boring person. The days, weeks, and years just disappear in some kind of boredom. [IN 10]

Sorrow, resignation, emotions of loss, and feelings of having limited freedom were also related to lack of PA\&E. Difficulties with being physically active led to feelings of hopelessness, frustration, and disappointment, and altogether negatively affected the mental and emotional state.

I am bound to my home. I am always at home and I know that I have to [...] [before the pain] I could walk around the neighborhood and even to the farmer to buy strawberries. I could walk long distances and I thought it was enjoyable. Not being able to do that now feels like a holdback. [IN 15]

\section{Physical activity - before and after pain}

The patients described PA\&E before the onset of pain and after the onset of pain as different experiences. Before the onset of pain, the patients had mainly positive experiences of performing PA\&E without limitations, from very intensive exercising to low intensive strolling.
Enjoyable PA\&E that resulted in a sense of well-being was preferred before the pain.

I always sported much, often ball games with my friends, volleyball, and floor ball mostly. I love everything that involves a ball. And I also exercised in ordinary group exercise, interval exercise, high-intensive-interval-training and many exercise classes. I also exercised at the gym $[\ldots]$ I found it relaxing and fun. [IN 14]

After the onset of pain, the experiences were less desirable. Once the chronic pain was established, the patients engaged less in PA\&E. Even if the patients were still trying to perform PA\&E, they experienced major difficulties with staying physically active.

And all this about running, jogging as I used to do, it is now gone. It is not possible now, I have tried. [IN 2]

These difficulties in performing PA\&E with pain led to a sense of failure. Despite extensive efforts to be physically active, the pain remained firmly as a bothersome limitation. An earlier habit of being physically active was brought up as essential for the attitude toward present PA\&E performance, which was thought to be beneficial for maintaining PA\&E.

\section{A struggle - difficulties and challenges}

Worries that PA\&E would increase the pain and would also lead to physical harm were expressed as barriers to perform PA\&E. This worry was reinforced by experiences of increased pain related to $P A \& E$ which caused ambivalence and reluctance toward performing PA\&E. Hesitance to engage in PA\&E because of a belief that pain should increase led to self-directed restrictions.

I am very, very scared to get hurt [...] It crackles from my knees [...] so I am really afraid that something will happen, that I will get a fracture or something. I am scared to death! [IN 8]

An uncontrollable barrier to PA\&E was the perception of a body not functioning properly, which made it impossible to perform certain PA\&E despite how much effort was devoted to performance.

There are activities for which a will of iron, or a desire, or a determination to perform the activity, will not help you.

The body is just simply not with you. [IN 14]

An inability to engage in PA\&E could also be related to lack of energy which was attributed to the pain, bad sleep, and social demands. A need to rest due to lack 
of energy was difficult to ignore. The chronic pain and energy deficiency led to avoidance of PA\&E even though a desire to be active and knowledge of benefits of PA\&E were present. That is, the only experienced choice was to be inactive and to rest.

Right there and then it is hard to win over the lack of energy.

It sort of wins over me. [IN 18]

In addition, patients found it difficult to identify the physical limits, which led to experiences of failure. Moreover, inability to adjust the dose and content of the PA\&E was brought up. A decreased level of PA\&E was often the result of such a failure of adapting the PA\&E to the current physical limits.

A lack of anticipated improvement and the impression of failure, especially in combination with increased pain after PA\&E, made it less appealing to perform PA\&E.

No, it feels like I have failed all the time. Afterwards [after the PA\&E] when I come home the pain got worse all the time [...]. Why should I continue when I do not get any results? [IN 1]

In addition, if PA\&E was experienced as boring or not in line with preferences, the motivation to perform PA\&E decreased. The patients could feel uncertain about what type of PA\&E to perform and how to perform it in the presence of pain. Barriers to performing PA\&E included a lack of will power to challenge the pain, energy deficiency, discomfort, poor mental status, lack of time, and difficulties in establishing new habits.

It is difficult, because during such a long time I have lived like this [with low level of PA\&E]. Now it is about getting my mind used to the fact that I actually am able to do more [...] you have to come to that insight yourself. [IN 18]

Difficulties in performing PA\&E even though the benefits were obvious and no hindrance was apparent were also highlighted. Although a plan to perform PA\&E regularly was defined, it could be troublesome to stick to the plan. However, it could also be beneficial to make plans for PA\&E. It was described that if the PA\&E was not an explicit and well-defined part of the plan for the day, it was even more likely that PA\&E would never be performed.

\section{Enabling physical activity}

The choice of an appropriate type and dose of PA\&E and to adjust the PA\&E when needed were crucial components for enabling PA\&E. In addition, positive experiences with decreased pain as a result of PA\&E enabled further performance of PA\&E.

The better effect I get from the exercise, the more [I exercise] [...] and if there is a setback, I just think anew and do otherwise. [IN 15]

To deliberately arrange crucial factors for the performance of PA\&E, and in a distinct way, take one step at the time during the performance contrary to having the whole activity in mind at the start were brought up as important. In addition, to pay attention to and respecting the physical limits were seen as prerequisites for proper adjustment of the PA\&E. The advantage of having alternative exercises was also expressed.

I cannot make excuses like "now it is hurting." Instead, I just think; "ok, it is hurting - then I do an easier exercise." I have several different exercises, so I cannot just give up now like I did before. [IN 17]

Mental focus was identified as essential for accomplishing PA\&E. Prioritizing PA\&E was seen as one aspect of mental focus on PA\&E, which was important for enabling PA\&E. When patients did not feel like engaging in PA\&E, they still thought it was important to fight on with the PA\&E by putting hesitation and rumination aside.

If I haven't had my goal, I don't think I would have recovered so quickly [...] I thought: this will not stop me. And I asked the physiotherapist how it should affect me - "Yes, but of course; you have to exercise a lot." And I did so! I exercised tremendously much at home. I had my exercise program, and I did everything! Exactly everything I did! [IN 5]

The will power to perform PA\&E was essential. It was important to set up manageable goals for PA\&E and to have a positive, reinforcing approach. The feeling of doing something good and to be satisfied with the performance could enable the performance of PA\&E:

I feel that I can be satisfied with that, I do not need to push myself too far [...] I might walk a bit slower and then I am thinking of being pleased with that. During the whole walk, I think; "It is ok, the weather is nice," or if it isn't; "It is alright even if it is raining, I have warm clothes." I always try to think in positive ways. [IN 13]

Furthermore, strategies for reinforcing the commitment to be active, for example, recording the planned and performed exercise in a diary, were sometimes effectively used. Social 
aspects were also described as making it easier to be physically active.

\section{[...] other people were around [at the gym] and you could share thoughts and talk to each other [...]. All of us had difficulties and when we opened up and started to talk [...] then we could say; "oh, we are really doing well!" Then it became easier. [IN 13]}

When PA\&E was viewed as an obligation or requirement, the likelihood of accomplishing the planned activities increased. Moreover, demands from, for example, family, children, pets, and horses made it easier to perform PA\&E.

\section{In need of continuous and active support}

The patients described experiences from contact with healthcare providers such as physiotherapists. The physiotherapy interventions were focused mainly on local symptoms in local body regions. Interventions intended to improve general function, PA\&E performance, and adherence to regular PA\&E were less common. The patients also noted that healthcare providers provided advice on how to manage pain. This advice was carefully considered, and if the advice seemed reasonable and fell within the patient's own preferences, the patients were more likely to followup on the advice. The advice could strengthen an existing attitude toward PA\&E, but rarely affected whether PA\&E was performed.

Experiences of only slight improvements as a result of the interventions were stated, and the patients also experienced a lack of explanation and information about the pain condition and possible treatment options.

I have been visiting physiotherapists, back specialists, physicians and so on. But nothing has helped me and I have never got any answers on what is wrong with me, why I have this pain. [IN 17]

Moreover, the patients noted that PA\&E treatment could worsen their pain rather than relieve their pain and blamed such failure of PA\&E treatment on a lack of individualized treatment and evaluation and misunderstandings from the healthcare providers.

I get the comments that "It is not dangerous" and that "you are not going to be worse." I do not believe it is dangerous [with PA\&E], but actually it happens that I become worse after PA\&E [...] I know that the pain will increase. And they [the healthcare providers] talk to me about pain that is not like my pain. And often they told me that I should not be afraid, but I am not afraid, I am not an anxious person, rather the opposite. [IN 3]

The patients talked about the desire of receiving continuous, extensive, and active support from the healthcare providers. Furthermore, it was seen as important that the healthcare providers were skilled in explaining various aspects of the pain and PA\&E treatment. A high level of professional knowledge in combination with an understanding, responsive, and empathetic attitude were important for establishing trust for the healthcare providers. The trust was especially required when it was necessary to involve both physical and mental aspects of the treatment.

I need someone to push me to get me over the hurdle [...] it can be of benefit if someone says "Do like this and you will get past the obstacle." I need someone to get me going so to say. And to guide me; "if it gets tough - do like this instead." [IN 7]

\section{Discussion}

Although PA\&E was highly valued, the participants experienced a marked decrease in PA\&E related to their chronic pain condition and this led to feelings of sorrow, loss of identity, and loss of autonomy. A struggle to be physically active was described and associated to both pain-related and general aspects. In addition, several strategies to enable PA\&E were identified. A high-quality interaction including active and continuous support was desired in contact with healthcare professionals.

In this study, a high value was assigned to PA\&E, a finding that confirms the results of previous qualitative research. ${ }^{39}$ Values are one factor that has been related to motivation, ${ }^{40}$ and according to the model of Acceptance and Commitment Therapy (ACT), ${ }^{41}$ values are one core component leading to committed actions toward a wanted situation. In this study, however, the high value ascribed to PA\&E was often not enough to achieve sustainable PA\&E at a desired level. Although a low level of PA\&E was related to dissatisfaction, disappointment, and inadequacy, thus not in line with the participant's values, it was still troublesome to perform regular PA\&E as desired. This finding might be understood in light of Self-Determination Theory (SDT) ${ }^{42-45}$ SDT is based on the belief that motivation can originate from extrinsic sources (when profits are derived from the behavior) as well as from internal drive, that is, intrinsic motivation (when the behavior is wanted in itself and performed even in the absence of profits or other external reward). The participants in this 
study had several motives to be physically active that can be attributed to extrinsic motivational factors such as potential gains received from the performance of PA\&E, including decreased pain, increased physical and mental health, and decreased risk of future illness. According to SDT, intrinsic motivation means that the behavior is favorable and wanted in itself, and this has been suggested to be the most stable motivational component in the long term. Intrinsic motivation for PA\&E in this study were possibly present when the participants performed the desired type of PA\&E, which were difficult. Thus, the intrinsic motivation was not as prominent in this study as the extrinsic motivation. Moreover, SDT includes psychological needs such as autonomy and competence as components probably underlying volition and behavior. In this study, autonomy and competence were likewise negatively affected, a finding that might relate to the difficulties with performing PA\&E. Furthermore, autonomy and competence regarding the performance of PA\&E might be associated with pain self-efficacy, which was rather low in this study. The participants in this study experienced that the pain was in charge, not their own will, and this finding is in line with the previous reported results. ${ }^{39}$ This experience, in combination with an unsatisfactory knowledge and skill to perform suitable PA\&E, might diminish the motivational effect of the high value of PA\&E.

The experience of less PA\&E in the presence of chronic pain is in line with quantitative studies that have shown that individuals with chronic pain are less physically active ${ }^{46}$ and perform less intense activities ${ }^{47}$ than individuals without pain. However, some studies show that the relation between chronic pain and performance of PA\&E depends on factors other than pain. That is, performance of PA\&E for patients suffering from chronic pain may be linked to psychological distress, coping strategies, ${ }^{48}$ and the daily pattern of PA\&E ${ }^{49}$ rather than to pain intensity per se. In this study, participants whose pain limited their PA\&E might be affected by recall bias; that is, they may overestimate their previous PA\&E level. Such an overestimation has been discussed in previous research. ${ }^{50}$ Moreover, the participants in this study experienced limited options regarding the preference-based choice of PA\&E. A participant's overall decrease in PA\&E could be related to increased disability preventing from performing desired PA\&E. This speculation is in line with an association between high disability and lower levels of PA\&E, which has been reported earlier in a review based on quantitative data on patients with chronic low back pain. ${ }^{51}$

Difficulties with accomplishing desirable PA\&E were present in this study and have also been described earlier. ${ }^{19}$
These difficulties can be discussed based on pain-related aspects and general aspects applicable on a wide range of behaviors. In this study, pain-related barriers to PA\&E include fear that PA\&E would lead to injuries and increased pain, concerns expressed as fear-avoidance beliefs. Fear-related avoidance of PA\&E in participants with chronic pain is well recognized ${ }^{19,39,52-54}$ and is theoretically described in the fear avoidance model. ${ }^{55,56}$ Qualitative research has reported a fear-related barrier to PA\&E, for individuals who had no previous pain, but experienced pain after participating in PA\&E. ${ }^{57}$ In this study, expected increase in pain led to hesitance and avoidance of PA\&E due to discomfort and an unwillingness to experience more pain. Similar results have been described for participants with chronic pain receiving a physical activity prescription from their general practioner. ${ }^{19}$ In addition, one study has described that avoidance of activity in the presence of pain was not constantly linked to fear but rather to an overall weighing of benefits against harms. ${ }^{39}$ Thus, these findings about pain-related avoidance of PA\&E also in the absence of fear agree with the proposals of adjustments of the fear avoidance model. ${ }^{58}$ In this study, avoidance of PA\&E related to pain was not described as changing over time, rather the avoidance as well as the emotion of fear was described as existing side by side with rational thoughts about the benefits of PA\&E. These findings contradict the previous descriptions about re-interpretation of pain associated with PA\&E, from a sign of danger to the need for rest and modification of PA\&E. ${ }^{59}$

The difficulties in obtaining the levels of PA\&E as desired might be described as an intention-behavior gap. ${ }^{60-62}$ The gap constitutes the discrepancy between the intention to perform PA\&E and the real PA\&E behavior. This gap was evident in this study; although the participants desired to accomplish PA\&E, they often did not engage in PA\&E. However, the experiences described in this study provide no further suggestions on the underlying mechanisms of the intentionbehavior gap. In the presence of pain and energy deficiency, the participants in this study were often physically inactive, even though they understood that PA\&E would probably be beneficial for their health and well-being in the long term. This finding elucidates the difficulties with acting on longterm goals, a well-known issue described in the literature on behavioral psychology.

A struggle for being physically active was apparent in this study. Likewise, actions of staying active and performing PA\&E despite chronic pain have been described earlier. ${ }^{59}$ A range of strategies to enable PA\&E was described by the participants in this study. Planning and purposefulness 
were found important for the performance of PA\&E. These factors are also present in the model Health Action Process Approach $^{63,64}$ in which motivation and volition precede the performance of PA\&E. In this model, volition includes planning, action-control (transfer intention into action sequences to accomplish and maintain certain behavior) and maintaining self-efficacy, a definition similar to this study's findings. In this study, planning and purposefulness could also be understood in relation to $\mathrm{ACT},{ }^{41}$ where commitment is a dominating prerequisite for desired actions. If the desired action is going to be fulfilled, planning and purposefulness should preferably be underpinned by psychological flexibility. ${ }^{41}$ In this study, there was a tendency toward psychological inflexibility, a mind-set that might be a barrier to PA\&E efforts, and performing PA\&E with respect to one's own limits (ie, pacing) ${ }^{65-67}$ was a self-developed coping strategy that enabled PA\&E. The importance of respecting physical limits to achieve a subjectively effective pacing has been reported earlier. ${ }^{68}$ Having positive experiences of PA\&E was experienced as beneficial for enabling PA\&E. This positive effect of performance accomplishment is also found in Bandura's social-cognitive theory, ${ }^{69,70}$ which describes how positive expectations of personal efficacy benefit desired behavior. In addition, self-judgment is considered essential for self-regulation of behavior, ${ }^{70}$ which is in line with the result of this study where the participants expressed the importance of reinforcing their desired behaviors during and after PA\&E. Depression and anxiety measured by HADS were not prominent in our group (HADS depression score were 6.5 [median]), this low depression score might have favored proper self-judgment as depression can affect selfjudgment negatively. ${ }^{71}$

This study found that patients with chronic pain desired high-quality interactions with healthcare providers, for example, regarding responsiveness and trust, and for explaining the pain condition and treatment options. This finding is in line with the need for an individually developed treatment, including understandable information about the pain condition, ${ }^{72}$ and earlier descriptions about a good patient-professional interaction for participants with chronic pain. ${ }^{73}$ In addition, in this study, the participants desired an active, engaged, and goal-directed support from healthcare providers, to help them overcome physical and mental barriers of PA\&E and to ensure a progress of the PA\&E treatment. Participants in this study emphasized the importance of an individual and personal focus in the treatment of the chronic pain. This might reflect the importance of good collaboration and mutual agreement regarding interventions and intervention goals between patient and healthcare providers as reported earlier in a therapeutic and counseling setting. ${ }^{74}$

\section{Methodological considerations}

This study used a qualitative content analysis ${ }^{36,37}$ with an inductive approach and a certain level of interpretation, ${ }^{38}$ and the analysis took its start close to the interview text. The content of the interviews was condensed and abstracted, and the final result represents to some extent a latent description. Throughout the design, analysis, and reporting phases, trustworthiness was carefully strived for based on credibility, transferability, dependability, and confirmability. ${ }^{75}$ The whole research process relied on continuous discussions and consensus by the authors (primarily LK and BL) while analyzing the data to strengthen the quality and trustworthiness of the study.

The interview data were based on a population of participants with chronic pain conditions. All the participants suffered from chronic pain for several years and were referred to a pain clinic; hence, they serve as a reliable source of qualitative information fulfilling the aim of the study. The strength of the study is the richness of information in the interview data, which may reflect that the interview guide and the performance of the interviews were appropriate for the aim of the study.

The purpose of this study was to increase the knowledge about PA\&E, an issue considered as a good and desirable behavior by society, and this might speculatively have contributed to selection bias. Thus, individuals who thought that their experiences and actions regarding PA\&E were not good enough might have denied participation. This bias might have resulted in an overestimation of the high value of PA\&E. The low number of men in the study group should be considered when interpreting the results. In addition, the scant information on the participants who did not want to participate could be a limitation of the study.

\section{Conclusion}

Physical activity was highly valued in daily life although experiences of PA\&E were characterized by difficulties and failure. A will to engage in desired PA\&E was apparent, but it was seldom successful even though the participants tried a variety of strategies. This intention-behavior gap identified might be related to the pain condition as well as to motivational aspects, self-efficacy, and action-control, a conclusion that requires careful analysis and support when PA\&E is applied as treatment for chronic pain. Abundant contact with healthcare providers was described, although the participants also experienced a lack of high-quality interactions with the 
healthcare providers as well as a lack of improvement of their pain condition. To address these deficiencies in the treatment of chronic pain, healthcare providers should aim to collaborate with the patients to develop individualized strategies that help the patients to accomplish their PA\&E goals and PA\&E treatment prescriptions. Future research should investigate interventions that recognize and decrease the intention-behavior gap in connection with PA\&E as treatment for chronic pain.

\section{Acknowledgements}

The present study was supported by grants from the Swedish Council for Working Life and Social Research (2007-0760), AFA Insurance (140341), Swedish Research Council (20142979), and County Council of Östergötland (LiO-536211). The funding bodies had no role with respect to the study design and the collection, analysis, and interpretation of data. In addition, the funding bodies also had no input in the report writing and the final decision to submit the paper for publication.

\section{Author contributions}

All the authors have contributed to preparing the manuscript according to the International Committee of Medical Journal Editors (ICMJE) criteria for authorship. All authors contributed toward data analysis, drafting and critically revising the paper, gave final approval of the version to be published, and agree to be accountable for all aspects of the work.

\section{Disclosure}

The authors report no conflicts of interest in this work.

\section{References}

1. Breivik H, Collett B, Ventafridda V, Cohen R, Gallacher D. Survey of chronic pain in Europe: prevalence, impact on daily life, and treatment. Eur J Pain. 2006;10(4):287-333.

2. Van Hecke O, Torrance N, Smith BH. Chronic pain epidemiology and its clinical relevance. Br J Anaesth. 2013;111(1):13-18.

3. Turk DC, Wilson HD, Cahana A. Treatment of chronic non-cancer pain. Lancet. 2011;377(9784):2226-2235.

4. Turk DC, Adams LM. Using a biopsychosocial perspective in the treatment of fibromyalgia patients. Pain Manag. 2016;6(4):357-369.

5. Geneen LJ, Moore RA, Clarke C, Martin D, Colvin LA, Smith BH. Physical activity and exercise for chronic pain in adults: an overview of Cochrane Reviews. Cochrane Database Syst Rev. 2017;1:Cd011279.

6. Caspersen CJ, Powell KE, Christenson GM. Physical activity, exercise, and physical fitness: definitions and distinctions for health-related research. Public Health Rep. 1985;100(2):126-131.

7. Ambrose KR, Golightly YM. Physical exercise as non-pharmacological treatment of chronic pain: Why and when. Best Pract Res Clin Rheumatol. 2015;29(1):120-130.

8. Busch AJ, Schachter CL, Overend TJ, Peloso PM, Barber KA. Exercise for fibromyalgia: a systematic review. $J$ Rheumatol. 2008;35(6):1130-1144.

9. Busch AJ, Webber SC, Richards RS, et al. Resistance exercise training for fibromyalgia. Cochrane Database Syst Rev. 2013;12:CD010884.
10. Bystrom MG, Rasmussen-Barr E, Grooten WJ. Motor control exercises reduces pain and disability in chronic and recurrent low back pain: a meta-analysis. Spine. 2013;38(6):E350-E358.

11. Saragiotto BT, Maher CG, Yamato TP, et al. Motor control exercise for chronic non-specific low-back pain. Cochrane Database Syst Rev. 2016;1:Cd012004.

12. Hagen KB, Dagfinrud H, Moe RH, et al. Exercise therapy for bone and muscle health: an overview of systematic reviews. BMC Med. 2012;10(1):1-11.

13. Gross A, Kay TM, Paquin JP, et al. Exercises for mechanical neck disorders. Cochrane Database Syst Rev. 2015;1:CD004250.

14. Jordan JL, Holden MA, Mason EE, Foster NE. Interventions to improve adherence to exercise for chronic musculoskeletal pain in adults. Cochrane Database Syst Rev. 2010;1:CD005956.

15. McLean SM, Burton M, Bradley L, Littlewood C. Interventions for enhancing adherence with physiotherapy: a systematic review. Man Ther. 2010;15(6):514-521.

16. Rhodes RE, Warburton DE, Murray H. Characteristics of physical activity guidelines and their effect on adherence: a review of randomized trials. Sports Med. 2009;39(5):355-375.

17. Kwasnicka D, Dombrowski SU, White M, Sniehotta F. Theoretical explanations for maintenance of behaviour change: a systematic review of behaviour theories. Health Psychol Rev. 2016;10(3):277-296.

18. Jack K, McLean SM, Moffett JK, Gardiner E. Barriers to treatment adherence in physiotherapy outpatient clinics: a systematic review. Man Ther. 2010;15(3):220-228.

19. Joelsson M, Bernhardsson S, Larsson ME. Patients with chronic pain may need extra support when prescribed physical activity in primary care: a qualitative study. Scand J Prim Health Care. 2017;35(1):64-74.

20. Slade SC, Patel S, Underwood M, Keating JL. What are patient beliefs and perceptions about exercise for nonspecific chronic low back pain? A systematic review of qualitative studies. Clin J Pain. 2014;30(11):995-1005.

21. Patton MQ. Qualitative Research and Evaluation Methods: Integrating Theory and Practice: The Definitive Text of Qualitative Inquiry Frameworks and Options. $4^{\text {th }}$ ed. Thousand Oaks, CA: SAGE Publications, Inc.; 2015.

22. World Medical Association. World Medical Association Declaration of Helsinki: ethical principles for medical research involving human subjects. JAMA. 2013;310(20):2191-2194.

23. Treede RD, Rief W, Barke A, et al. A classification of chronic pain for ICD-11. Pain. 2015;156(6):1003-1007.

24. Craig CL, Marshall AL, Sjostrom M, et al. International Physical Activity Questionnaire: 12-country reliability and validity. Med Sci Sports Exerc. 2003;35(8):1381-1395.

25. International Physical Activity Questionnaire. Available from: https:// sites.google.com/site/theipaq/. Accessed October 28, 2017.

26. Bjelland I, Dahl AA, Haug TT, Neckelmann D. The validity of the hospital anxiety and depression scale. an updated literature review. $J$ Psychosom Res. 2002;52(2):69-77.

27. Zigmond AS, Snaith RP. The hospital anxiety and depression scale. Acta Psychiatr Scand. 1983;67(6):361-370.

28. Nicholas MK. The pain self-efficacy questionnaire: taking pain into account. Eur J Pain. 2007;11(2):153-163.

29. Waddell G, Newton M, Henderson I, Somerville D, Main CJ. A FearAvoidance Beliefs Questionnaire (FABQ) and the role of fear-avoidance beliefs in chronic low back pain and disability. Pain. 1993;52(2): $157-168$.

30. Williamson E. Fear avoidance beliefs questionnaire (FABQ). Aust $J$ Physiother. 2006;52(2):149.

31. Fritz JM, George SZ. Identifying psychosocial variables in patients with acute work-related low back pain: the importance of fear-avoidance beliefs. Phys Ther. 2002;82(10):973-983.

32. Wicksell RK, Olsson GL, Melin L. The chronic pain acceptance questionnaire (CPAQ) - further validation including a confirmatory factor analysis and a comparison with the Tampa Scale of Kinesiophobia. Eur J Pain. 2009;13(7):760-768. 
33. Wolfe F, Smythe HA, Yunus MB, et al. The American College of Rheumatology 1990 criteria for the classification of fibromyalgia. Report of the Multicenter Criteria Committee. Arthritis Rheumat. 1990;33(2):160-172.

34. Kvale S, Brinkmann S. Den kvalitativa forskningsintervjun [The qualitative research interview]. Lund: Studentlitteratur, 2014. Swedish.

35. Elo S, Kyngas H. The qualitative content analysis process. JAdv Nurs. 2008;62(1):107-115.

36. Krippendorff K. Content Analysis: An Introduction to Its Methodology. 3rd ed. Thousand Oaks, CA; London: SAGE; 2013.

37. Graneheim UH, Lundman B. Qualitative content analysis in nursing research: concepts, procedures and measures to achieve trustworthiness. Nurs Educ Today. 2004;24(2):105-112.

38. Sandelowski M. Whatever happened to qualitative description? Res Nurs Health. 2000;23(4):334-340.

39. Schmidt A, Corcoran K, Grahame R, de CWAC. How do people with chronically painful joint hypermobility syndrome make decisions about activity? Br J Pain. 2015;9(3):157-166.

40. Karimi M, Clark AM. How do patients' values influence heart failure self-care decision-making? A mixed-methods systematic review. Int $J$ Nurs studies. 2016;59:89-104.

41. Hayes SC, Levin ME, Plumb-Vilardaga J, Villatte JL, Pistorello J. Acceptance and commitment therapy and contextual behavioral science: examining the progress of a distinctive model of behavioral and cognitive therapy. Behav Ther. 2013;44(2):180-198.

42. Ryan RM, Deci EL. Intrinsic and extrinsic motivations: classic definitions and new directions. Contemp Educ Psychol. 2000;25(1):54-67.

43. Deci EL, Ryan RM. Self-determination theory: a macrotheory of human motivation, development, and health. Can Psychol. 2008;49(3): $182-185$.

44. Teixeira PJ, Carraca EV, Markland D, Silva MN, Ryan RM. Exercise, physical activity, and self-determination theory: a systematic review. Int J Behav Nutr Phys Act. 2012;9:78.

45. Ryan RM, Deci EL. Self-determination theory and the facilitation of intrinsic motivation, social development, and well-being. Am Psychol. 2000;55(1):68-78

46. Segura-Jimenez V, Alvarez-Gallardo IC, Estevez-Lopez F, et al. Differences in sedentary time and physical activity between female patients with fibromyalgia and healthy controls: the al-Andalus project. Arthritis Rheum. 2015;67(11):3047-3057.

47. Kop WJ, Lyden A, Berlin AA, et al. Ambulatory monitoring of physical activity and symptoms in fibromyalgia and chronic fatigue syndrome. Arthritis Rheum. 2005;52(1):296-303.

48. Perruchoud C, Buchser E, Johanek LM, Aminian K, Paraschiv-Ionescu A, Taylor RS. Assessment of physical activity of patients with chronic pain. Neuromodulation. 2014;17(Suppl 1):42-47.

49. Griffin DW, Harmon DC, Kennedy NM. Do patients with chronic low back pain have an altered level and/or pattern of physical activity compared to healthy individuals? A systematic review of the literature. Physiotherapy. 2012;98(1):13-23.

50. van Weering M, Vollenbroek-Hutten MM, Kotte EM, Hermens HJ. Daily physical activities of patients with chronic pain or fatigue versus asymptomatic controls. A systematic review. Clin Rehabil. 2007;21(11):1007-1023.

51. Lin CW, McAuley JH, Macedo L, Barnett DC, Smeets RJ, Verbunt JA. Relationship between physical activity and disability in low back pain: a systematic review and meta-analysis. Pain. 2011;152(3):607-613.

52. Wertli MM, Rasmussen-Barr E, Held U, Weiser S, Bachmann LM, Brunner F. Fear-avoidance beliefs-a moderator of treatment efficacy in patients with low back pain: a systematic review. Spine J. 2014;14(11): 2658-2678.

53. Wertli MM, Rasmussen-Barr E, Weiser S, Bachmann LM, Brunner F. The role of fear avoidance beliefs as a prognostic factor for outcome in patients with nonspecific low back pain: a systematic review. Spine J. 2014;14(5):816.e814-836.e814.
54. Nijs J, Roussel N, Van Oosterwijck J, et al. Fear of movement and avoidance behaviour toward physical activity in chronic-fatigue syndrome and fibromyalgia: state of the art and implications for clinical practice. Clin Rheumatol. 2013;32(8):1121-1129.

55. Vlaeyen JW, Linton SJ. Fear-avoidance model of chronic musculoskeletal pain: 12 years on. Pain. 2012;153(6):1144-1147.

56. Vlaeyen JW, Linton SJ. Fear-avoidance and its consequences in chronic musculoskeletal pain: a state of the art. Pain. 2000;85(3):317-332.

57. Danielsen KK, Sundgot-Borgen J, Rugseth G. Severe obesity and the ambivalence of attending physical activity: exploring lived experiences. Qual Health Res. 2016;26(5):685-696.

58. Crombez G, Eccleston C, Van Damme S, Vlaeyen JW, Karoly P. Fearavoidance model of chronic pain: the next generation. Clin J Pain. 2012;28(6):475-483.

59. Damsgard E, Dewar A, Roe C, Hamran T. Staying active despite pain: pain beliefs and experiences with activity-related pain in patients with chronic musculoskeletal pain. Scand J Caring Sci. 2011;25(1):108-116.

60. Armitage CJ. Can the theory of planned behavior predict the maintenance of physical activity? Health Psychol. 2005;24(3):235-245.

61. Webb TL, Sheeran P. Does changing behavioral intentions engender behavior change? A meta-analysis of the experimental evidence. Psychol Bull. 2006;132(2):249-268.

62. Rhodes RE, Yao CA. Models accounting for intention-behavior discordance in the physical activity domain: a user's guide, content overview, and review of current evidence. Int J Behav Nutr Phys Act. 2015;12:9.

63. Schwarzer R, Lippke S, Luszczynska A. Mechanisms of health behavior change in persons with chronic illness or disability: the Health Action Process Approach (HAPA). Rehab Psychol. 2011;56(3):161-170.

64. Arbour-Nicitopoulos KP, Duncan M, Remington G, Cairney J, Faulkner GE. Development and reliability testing of a health action process approach inventory for physical activity participation among individuals with schizophrenia. Front Psychiatr. 2014;5:68.

65. Nielson WR, Jensen MP, Karsdorp PA, Vlaeyen JW. Activity pacing in chronic pain: concepts, evidence, and future directions. Clin J Pain. 2013;29(5):461-468.

66. Nielson WR, Jensen MP, Karsdorp PA, Vlaeyen JW. A content analysis of activity pacing in chronic pain: what are we measuring and why? Clin J Pain. 2014;30(7):639-645.

67. Jamieson-Lega K, Berry R, Brown CA. Pacing: a concept analysis of the chronic pain intervention. Pain Res Manag. 2013;18(4):207-213.

68. Antcliff D, Keeley P, Campbell M, Woby S, McGowan L. Exploring patients' opinions of activity pacing and a new activity pacing questionnaire for chronic pain and/or fatigue: a qualitative study. Physiotherapy. 2016;102(3):300-307.

69. Bandura A, Adams NE, Beyer J. Cognitive processes mediating behavioral change. J Personal Soc Psychol. 1977;35(3):125-139.

70. Tougas ME, Hayden JA, McGrath PJ, Huguet A, Rozario S. A systematic review exploring the social cognitive theory of self-regulation as a framework for chronic health condition interventions. PLoS One. 2015;10(8):e0134977.

71. Beck AT, Alford BA. Depression: Causes and Treatment. 2nd ed. Philadelphia, PA: University of Pennsylvania Press; 2009.

72. Stenner R, Swinkels A, Mitchell T, Palmer S. Exercise prescription for non-specific chronic low back pain (NSCLBP): a qualitative study of patients' experiences of involvement in decision making. Physiotherapy. 2016;102(4):339-344.

73. Oosterhof B, Dekker JHM, Sloots M, Bartels EAC, Dekker J. Success or failure of chronic pain rehabilitation: the importance of good interaction - a qualitative study under patients and professionals. Disabil Rehabil. 2014;36(22):1903-1910.

74. Vowles KE, Thompson M. The patient-provider relationship in chronic pain. Curr Pain Headache Rep. 2012;16(2):133-138.

75. Guba EG. ERIC/ECTJ Annual Review Paper: criteria for assessing the trustworthiness of naturalistic inquiries. Educ Commun Technol. 1981;29(2):75-91. 
The Journal of Pain Research is an international, peer reviewed, open access, online journal that welcomes laboratory and clinical findings in the fields of pain research and the prevention and management of pain. Original research, reviews, symposium reports, hypothesis formation and commentaries are all considered for publication.
Dovepress

The manuscript management system is completely online and includes a very quick and fair peer-review system, which is all easy to use. Visit http://www.dovepress.com/testimonials.php to read real quotes from published authors. 